\title{
Intermediate Cervical Plexus Block for Carotid Endarterectomy: A Case Series of the Spread of Injectate
}

\author{
Mattias Casutt ${ }^{1 *}$, Kathrin Job ${ }^{1}$, Jonas Beutler ${ }^{1}$, Jan Duwe ${ }^{2}$, Patrick Veit ${ }^{3}$ and Christoph Konrad ${ }^{1}$
}

${ }^{1}$ Institute of Anesthesiology and Intensive Care, Kantonsspital, Lucerne, Switzerland

${ }^{2}$ Department of Surgery, Kantonsspital, Lucerne, Switzerland

${ }^{3}$ Department of Radiology, Kantonsspital, Lucerne, Switzerland

\begin{abstract}
Background: The case series illustrates the spread of local anesthetic resulting from a standardized singleinjection technique of intermediate cervical plexus block before carotid endarterectomy

Methods: 14 consecutive patients scheduled for elective carotid endarterectomy were included Standardized intermediate cervical plexus block was performed on the level of $\mathrm{C} 5 / \mathrm{C} 6$ at the posterior border of the sternocleidomastoid muscle. A mixture of $20 \mathrm{ml}$ Ropivacaine $0.75 \%, 20 \mathrm{ml}$ Prilocaine $1 \%$ and $8 \mathrm{ml}$ lopromidum (iodine-concentration $300 \mathrm{mg} / \mathrm{ml}$ ) was injected. The direction of the injection was defined as cranial, medial and caudal behind the sternocleidomastoid muscle in a depth of $1-1.5 \mathrm{~cm}$. Subsequently, after 30 minutes, a CT-scan of the head and neck region and upper thorax was completed to evaluate the distribution of the injectate in a threedimensional reconstruction.
\end{abstract}

Results: The spread of the injectate ranged from the top edge of cervical vertebral body 1 to the bottom edge of thoracic vertebral body 3 . The reproduced volume of $75260(5407) \mathrm{mm}^{3}$ (SD) possessed a maximal craniocaudal spread of $125(24) \mathrm{mm}$ in the sagital plane $81(13) \mathrm{mm}$ and in the coronal plane $43(13) \mathrm{mm}$. The minimal distance to the skin was $0.9(1.0) \mathrm{mm}$. The patients judged the block to be sufficient under our protocol. Therefore, no patient required conversion to general anesthesia.

Conclusion: Intermediate cervical plexus block is associated with an extensive spread of injectate that transverses the deep cervical fascia. The distribution pattern and the sensory and motor blockade level of this intermediate cervical plexus block seems to be sufficient for surgery and is of minor risk compared to the deep cervical plexus block.

Keywords: Carotid endarterectomy; Cervical plexus block; Spread of local anesthetic; Three-dimensional reconstruction

Abbreviations: CEA: Carotid Endarterectomy; CT: Computed Tomography; SD: Standard Deviation

\section{Introduction}

Possible perioperative complications of carotid surgery are myocardial or cerebrovascular infarctions. Different anesthetic procedures are performed for carotid endarterectomy (CEA) [1]. A multicenter, randomized controlled trial did not find any difference in outcome between general and regional anesthesia [2]. There are advantages and disadvantages for both kinds of anesthesia. Patients under general anesthesia have safe control of airways, no pain or anxiety during the operation, and anesthetic agents may offer a degree of neuroprotection [3]. On the other hand, patient population undergoing CEA possesses numerous comorbidities with a high incidence of severe coronary disease and intraoperative propensity for arterial hypotension $[2,4]$ Shunts should protect the brain from stroke during low cerebral blood flow in the carotid cross-clamping phase, but they damage the arterial wall which might result in cerebral embolism. Intraoperative neurological monitoring under general anesthesia, such as stump pressure measurement (blood pressure measured in the internal carotid artery), EEG or somatosensory evoked potentials, reveal poor sensitivity and specifity regarding the requirement for shunt placement compared to the awake patient $[5,6]$. Therefore, regional anesthesia has become the favored anesthesia technique for CEA in the last years as it allows direct neurological monitoring [7] and provides effective pain relief with a higher patient satisfaction postoperatively [8].
Carotid surgery requires blockade of the cervical nerves C2-4. This may be performed by using a intermediate cervical plexus block, a deep cervical plexus block or a combination of both [9]. The deep block is technically difficult, needs one to three injections, results more frequently in conversion to general anesthesia and is associated with potentially serious complications, such as injection of the local anesthetic epidurally, subarachnoidally or into the vertebral artery [9]. In contrast, the intermediate block is technically easier and can be performed more rapidly. Clinical trials found, that the intermediate block is equally effective $[7,10]$ or even superior [9] compared to the deep block. Additionally, anatomical studies with dye injections proved that the deep cervical fascia is a penetrable barrier $[11,12]$

The purpose of this case series was to show the spread of injected local anesthetic after intermediate cervical plexus blockade in a three-dimensional CT-scan. We examined in vivo whether the deep cervical fascia was traversed by the local anesthetic. According to our

${ }^{*}$ Corresponding author: Mattias Casutt, Institute of Anesthesiology and Intensive Care, Kantonsspital Lucerne Spitalstrasse, $\mathrm{CH}-6000$ Lucerne 16, Switzerland, Tel: +41 4120549 46; Fax: +41 4120549 49; E-mail: mattias.casutt@ksl.ch

Received January 27, 2011; Accepted February 20, 2011; Published February 21, 2011

Citation: Casutt M, Job K, Beutler J, Duwe J, Veit P, et al. (2011) Intermediate Cervical Plexus Block for Carotid Endarterectomy: A Case Series of the Spread of Injectate. J Anesthe Clinic Res 2:123. doi:10.4172/2155-6148.1000123

Copyright: ( 2011 Casutt $\mathrm{M}$, et al. This is an open-access article distributed unde the terms of the Creative Commons Attribution License, which permits unrestricted use, distribution, and reproduction in any medium, provided the original author and source are credited. 


\begin{tabular}{|c|c|c|c|c|c|c|c|c|}
\hline & Age (y) & BMI $\left(\mathrm{kg} / \mathrm{m}^{2}\right)$ & $\begin{array}{l}\text { Minimal distance of } \\
\text { the contrast agent } \\
\text { to the skin }(\mathrm{mm})\end{array}$ & $\begin{array}{l}\text { Craniocaudal spread in } \\
\text { relation to the spine }\end{array}$ & $\begin{array}{l}\text { Craniocaudal spread } \\
(\mathrm{mm})\end{array}$ & Volume $\left(\mathrm{mm}^{3}\right)$ & $\begin{array}{l}\text { Maximal contrast } \\
\text { spread in the } \\
\text { sagittal plane }(\mathrm{mm})\end{array}$ & $\begin{array}{l}\text { Maximal contrast } \\
\text { spread in the coronal } \\
\text { plane }(\mathrm{mm})\end{array}$ \\
\hline Patient $1 / \mathrm{m}$ & 79 & 25 & 1 & $\begin{array}{l}\text { middle of CVB3 - } \\
\text { lower edge of TVB3 }\end{array}$ & 102 & 70236 & 77 & 33 \\
\hline Patient 2 / m & 70 & 22 & 1 & $\begin{array}{l}\text { middle of CVB2 - } \\
\text { upper edge of TVB3 }\end{array}$ & 148 & 82560 & 79 & 25 \\
\hline Patient $3 / \mathrm{m}$ & 77 & 29 & 2 & $\begin{array}{l}\text { upper edge of CVB2 - } \\
\text { lower edge of TVB1 }\end{array}$ & 101 & 73038 & 54 & 33 \\
\hline Patient 4 / m & 73 & 29 & 0 & $\begin{array}{l}\text { lower edge of CVB3 - } \\
\text { lower edge of TVB3 }\end{array}$ & 124 & 86759 & 84 & 36 \\
\hline Patient $5 / \mathrm{m}$ & 73 & 29 & 1 & $\begin{array}{l}\text { lower edge of CVB2 - } \\
\text { middle of TVB2 }\end{array}$ & 133 & 79701 & 74 & 36 \\
\hline Patient 6 / m & 76 & 24 & 3 & $\begin{array}{l}\text { upper edge of CVB4 - } \\
\text { lower edge of TVB3 }\end{array}$ & 135 & 66009 & 94 & 50 \\
\hline Patient 7 / f & 72 & 30 & 0 & $\begin{array}{l}\text { middle of CVB2 - } \\
\text { lower edge of TVB2 }\end{array}$ & 128 & 70518 & 89 & 74 \\
\hline Patient 8 / m & 83 & 21 & 2 & $\begin{array}{l}\text { middle of CVB2 - } \\
\text { middle of TVB4 }\end{array}$ & 169 & 74025 & 86 & 56 \\
\hline Patient 9 / f & 74 & 21 & 0 & $\begin{array}{l}\text { lower edge of CVB3 - } \\
\text { middle of TVB2 }\end{array}$ & 86 & 77219 & 102 & 35 \\
\hline Patient $10 / \mathrm{m}$ & 78 & 26 & 0 & $\begin{array}{l}\text { lower edge of CVB1 - } \\
\text { lower edge of TVB3 }\end{array}$ & 157 & 72248 & 79 & 44 \\
\hline Patient $11 / \mathrm{m}$ & 74 & 29 & 2 & $\begin{array}{l}\text { upper edge of CVB1 - } \\
\text { upper edge of TVB1 }\end{array}$ & 138 & 75045 & 68 & 37 \\
\hline Patient 12 / m & 67 & 31 & 0 & $\begin{array}{l}\text { middle of CVB2 - } \\
\text { middle of TVB1 }\end{array}$ & 108 & 74438 & 72 & 41 \\
\hline Patient 13 / f & 61 & 18 & 0 & $\begin{array}{l}\text { lower edge of CVB1 - } \\
\text { lower edge of TVB2 }\end{array}$ & 123 & 79202 & 70 & 40 \\
\hline Patient 14 / m & 78 & 29 & 0 & $\begin{array}{l}\text { lower edge of CVB3 - } \\
\text { upper edge of TVB1 }\end{array}$ & 103 & 72969 & 103 & 57 \\
\hline mean (SD) & $\begin{array}{l}74 \\
(5)\end{array}$ & $\begin{array}{l}26 \\
(4)\end{array}$ & $\begin{array}{l}\mathbf{0 . 9} \\
(1.0)\end{array}$ & & $\begin{array}{l}125 \\
(24)\end{array}$ & $\begin{array}{l}75260 \\
(5407)\end{array}$ & $\begin{array}{l}81 \\
(13)\end{array}$ & $\begin{array}{l}43 \\
(13)\end{array}$ \\
\hline
\end{tabular}

$\mathrm{BMI}=$ body mass index CVB = cervical vertebral body; $f=$ female; $m=$ male; TVB = thoracic vertebral body

Table 1: Demographic data of the 14 patients with radiological contrast agent spread.

knowledge, such a deep cervical fascia penetrability of local anesthetic in vivo has not yet been described.

\section{Materials and Methods}

After approval by the institutional ethics committee (Kantonale Ethik-Kommission des Kantons Luzern, protocol number 708) and written informed consent, 14 consecutive American Society of Anesthesiologists class II-III patients undergoing elective CAE were enrolled into this study $\left(74 \pm 5 \mathrm{yr}\right.$ of age and $26 \pm 4 \mathrm{~kg} / \mathrm{m}^{2}$ body mass index). Exclusion criteria included known bleeding disorder, history of allergy to local anesthetics or to iodized X-ray contrast mediums, local sepsis, acute cardiac-decompensation, severe respiratory insufficiency or known diaphragmatic motion abnormalities.

After routine monitoring of five-lead electrocardiography, noninvasive blood pressure, pulse oxymetry and peripheral insertion of a $18 \mathrm{G}$ intravenous cannula, a $20 \mathrm{G}$ cannula was placed in the contralateral radial artery for continuous blood pressure monitoring. $2 \mathrm{~L} / \mathrm{min}$ oxygen was administerd nasally. Regional anesthesia was performed by two senior anesthesiologists with patients in supine position and the head turned slightly away from the side of surgery. After skin disinfection, an atraumatic needle for peripheral nerve blocks (Stimuplex D 25Gx35mm, B. Braun, Melsungen, Germany) was inserted on the level of $\mathrm{C} 5 / \mathrm{C} 6$ at the horizontal projection of the cricoid cartilage on the line tracing the posterior border of the sternocleidomastoid muscle. The direction of injection was defined as fan-shaped cranial in chin direction, medial and caudal behind the sternocleidomastoid muscle in a depth of 1-1.5 cm. We administered a mixture of $20 \mathrm{ml}$ Ropivacaine $0.75 \%, 20 \mathrm{ml}$ Prilocaine $1 \%$ and $8 \mathrm{ml}$ Iopromidum (triiodized, non-ionic, water-soluble X-ray contrast medium with an iodine-concentration of $300 \mathrm{mg} / \mathrm{ml}$ ). In all three described prick directions we administered $16 \mathrm{ml}$ of the mixture. $30 \mathrm{~min}$ later, a CT-scan of the head neck region and upper thorax was completed to evaluate the distribution of the injectate in a three-dimensional reconstruction. During the operation, all patients had a Remifentanyl drip of $0.02-0.2 \mu \mathrm{g} / \mathrm{kg} / \mathrm{min}$. Neurological monitoring was provided by spontaneous communication and periodic request to squeeze a rubber duckling. At the end of the operation, local infiltration with Lidocaine $1 \%$ to insert the drainage tube from the operation field via jugulum had to be performed by the surgeons routinely as this skin area was not part of the intermediate cervical plexus block. In scanographic sequential cross section we analyzed the cranial-caudal spread related to the cervical spine, the maximal spread in the sagittal and coronal plane, the cumulative distribution volume, the minimal distance to the skin and whether there was a sheathing of the carotis artery or not (Table 1).

Statistical analysis was done using the commercially available software package MS-Excel XP 2003 (Microsoft Corporation, Redmond, WA 98052 USA). Data are depicted as mean and standard deviation (SD).

\section{Results}

The medial cranio-caudal spread of the contrast medium was averaged $125(24) \mathrm{mm}$ with a maximal cranial spread to the top edge of cervical vertebral body 1 and a maximal caudal spread to the bottom edge of thoracic vertebral body 3 . In the sagittal plane there was a medium distribution of averaged $81(13) \mathrm{mm}$ and in the coronal plane of averaged $43(13) \mathrm{mm}$. The average distribution volume in the scanographic sequential cross section was $75^{\prime} 260$ (5407) $\mathrm{mm}^{3}$ (Figure 1 and 2). In the sample, we measured a medium distance of $0.9(1.0) \mathrm{mm}$ between injectate and skin, whereat in 7 patients $(50 \%)$ the injectate adjoined the skin. In one out of the total of 14 patients there was a local anesthetic sheating of the carotid artery over a distance of $34 \mathrm{~mm}$. No patient required conversion to general anesthesia. 


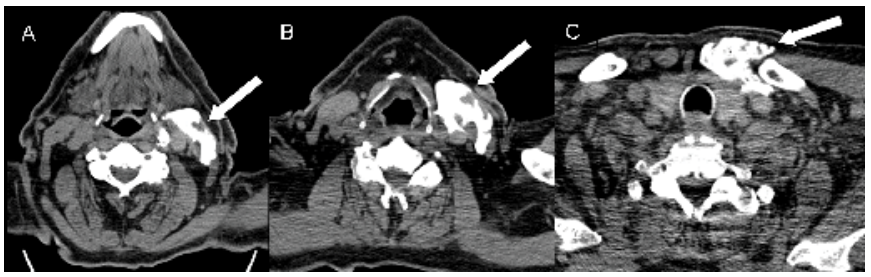

Figure 1: Axial native CT images of the left sided contrast media/anaesthetic injection at three different levels of the neck (A: submandibular, B: mid neck laryngeal level, $\mathrm{C}$ : superior thorax aperture). No ring like union of the contrast media around the carotid artery was achieved in this case. Contrast media extents down to the left sternal-clavicular joint.

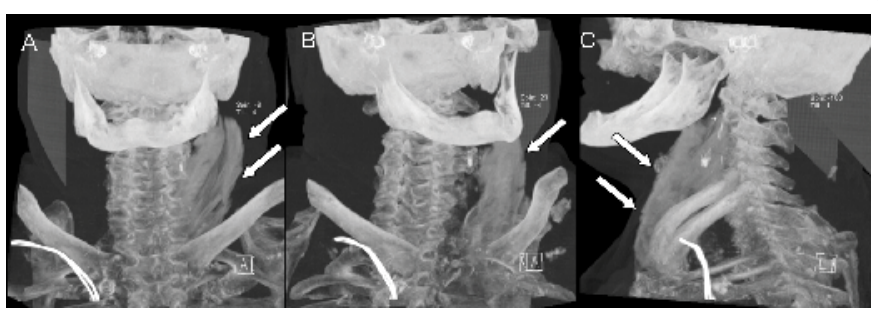

Figure 2: Three-dimensional images of the left sided contrast media/ anaesthetic injection from three different angles (A: anterior, B: right oblique anterior, C: left lateral/posterior oblique). Contrast media distribution is pointed out by white arrows. Additional central subclavian line on the right side.

\section{Discussion}

In the current case series, we demonstrated the spread of injected local anesthetic after standardized intermediate cervical plexus blockade using a three-dimensional CT-scan reconstruction of the injectate. Thereby, we confirmed the anatomical studies visually in vivo which showed by the use of dye injection that the deep cervical fascia is a penetrable barrier for local anesthetics $[11,12]$.

The cervical block can either be superficial or below the deep cervical fascia. The superficial block should be termed "intermediate" in an anatomically correct manner because the needle pierces the investing fascia of the neck $[9,13]$. As mentioned above, the deep block technique is more difficult to perform, is more likely to evoke serious complications but is not more successful compared to the intermediate block, and intraoperatively, surgeons were unable to distinguish the type of block used $[7,9,10,14,15]$. A further advantage of the intermediate block is its rapid performance. After skin disinfection, we accomplished one skin puncture without sterile medical drape, ultrasound use or nerve-stimulation. In the literature, we found different volumes of local anesthetic used for cervical blocks. It varies between $10 \mathrm{ml} \mathrm{[16]} \mathrm{and}$ $80 \mathrm{ml}$ [17] with the majority between $20 \mathrm{ml}$ and $40 \mathrm{ml}[7,10,14,15,18$ 21] Certainly, patients with a higher dose could benefit in relation to postoperative analgesia [10]. In our study, we administered a total of $40 \mathrm{ml}$ of local anesthetics.

In the existing literature, we could find one further trial using three-dimensional scanographic reconstruction of the deep cervical block which included 6 patients receiving $40 \mathrm{ml}$ local anesthetic [19]. The authors showed a hemi cylinder-shape injectate spread of the local anesthetic with both ends stretched toward $\mathrm{C} 1$ and $\mathrm{C} 7$. They performed the deep cervical block with the assistance of a nerve stimulator and without muscular response below a current of $0.5 \mathrm{~mA}$ of the levator scapula muscle with needle position in the horizontal projection of the upper margin of the thyroid cartilage on the line tracting the posterior border of the sternocleidomastoid muscle. The additional digital pressure perpendicular to the sternocleidomastiod muscle during the injection period of three minutes could explain the lower local anesthetic spread compared to our observation which showed that the local anesthetic spread extended from $\mathrm{C} 1$ to $\mathrm{Th} 3$. In the aforementioned trial, 5 of 8 patients $(63 \%)$ described the maximum pain intraoperatively with a median of $30 \mathrm{~mm}$ (25-45) on a visual analog scale VAS, with VAS 0 corresponding to no pain and VAS 100 corresponding to maximum imaginable pain. We did not record VAS during surgery as the surgeons wanted to avoid disturbance of the patients during the operation. Additionally, a Remifentanyl drip was administered, for the patient to remain calm but still amenable during the operation. We would like to point out that our case series was designed to show the spread of the local anesthetic by use of a three-dimensional CT-scan reconstruction of the injectate and not to evaluate the effectiveness of the intermediate cervical plexus blockade. This has already been done in many previous investigations $[7,9,10]$ The patients judged the block to be sufficient under our protocol. Therefore, no patient required conversion to general anesthesia.

In conclusion, we showed in vivo the permeability of the deep cervical fascia for local anesthetics after intermediate cervical plexus blockade. The intermediate cervical plexus blockade can be performed rapidly, is sufficient for surgery according to our protocol and provides an alternative approach to the deep cervical block for CEA with a lower rate of complications.

Financial Support: Institute of Anesthesiology and Intensive Care, Kantonsspital Lucerne, Switzerland

Conflict of Interest: There are no conflicts of interests.

\section{References}

1. Howell SJ (2007) Carotid endarterectomy. Br J Anaesth 99 :119-131.

2. Lewis SC, Warlow CP, Bodenham AR, Colam B, Rothwell PM, et al. (2008) General anaesthesia versus local anaesthesia for carotid surgery (GALA): a multicentre, randomised controlled trial. Lancet 372: 2132-2142.

3. Payne RS, Akca O, Roewer N, Schurr A, Kehl F (2005) Sevoflurane-induced preconditioning protects against cerebral ischemic neuronal damage in rats. Brain Res 1034: 147-152.

4. McCleary AJ, Maritati G, Gough MJ (2001) Carotid endarterectomy; local or general anaesthesia? Eur J Vasc Endovasc Surg 22: 1-12.

5. Hans SS, Jareunpoon O (2007) Prospective evaluation of electroencephalography, carotid artery stump pressure, and neurologic changes during 314 consecutive carotid endarterectomies performed in awake patients. J Vasc Surg 45: 511-515

6. Schneemilch CE, Ludwig S, Ulrich A, Halloul Z, Hachenberg T (2007) [Somatosensory evoked potentials and biochemical markers of neuronal deficits in patients undergoing carotid endarterectomy under regional anesthesia] Zentralbl Chir 132: 176-182.

7. Hakl M, Michalek P, Sevcik P, Pavlikova J, Stern M (2007) Regional anaesthesia for carotid endarterectomy: an audit over 10 years. Br J Anaesth 99: 415-420.

8. Messner M, Albrecht S, Lang W, Sittl R, Dinkel M (2007) The superficial cervical plexus block for postoperative pain therapy in carotid artery surgery. $A$ prospective randomised controlled trial. Eur J Vasc Endovasc Surg 33: 50-54.

9. Pandit JJ, Satya-Krishna R, Gration P (2007) Superficial or deep cervical plexus block for carotid endarterectomy: a systematic review of complications. Br J Anaesth 99: 159-169.

10. Pandit JJ, Bree S, Dillon P, Elcock D, McLaren ID, et al. (2000) A comparison of superficial versus combined (superficial and deep) cervical plexus block for carotid endarterectomy: a prospective, randomized study. Anesth Analg 91: 781-786.

11. Nash L, Nicholson HD, Zhang M (2005) Does the investing layer of the deep cervical fascia exist? Anesthesiology 103: 962-968.

12. Pandit JJ, Dutta D, Morris JF (2003) Spread of injectate with superficial cervica plexus block in humans: an anatomical study. $\mathrm{Br} \mathrm{J}$ Anaesth 91:733-735. 
Citation: Casutt M, Job K, Beutler J, Duwe J, Veit P, et al. (2011) Intermediate Cervical Plexus Block for Carotid Endarterectomy: A Case Series of the Spread of Injectate. J Anesthe Clinic Res 2:123. doi:10.4172/2155-6148.1000123

13. Telford RJ, Stoneham MD (2004) Correct nomenclature of superficial cervical plexus blocks. Br J Anaesth 92: 775-776.

14. Stoneham MD, Doyle AR, Knighton JD, Dorje P, Stanley JC (1998) Prospective, randomized comparison of deep or superficial cervical plexus block for carotid endarterectomy surgery. Anesthesiology 89: 907-912.

15. Barone M, Diemunsch P, Baldassarre E, Oben WE, Ciarlo M, et al. (2010) Carotid endarterectomy with intermediate cervical plexus block. Tex Heart Inst J 37: 297-300.

16. Winnie AP, Ramamurthy S, Durrani Z, Radonjic R (1975) Interscalene cervical plexus block: a single-injection technic. Anesth Analg 54: 370-375.

17. Kefalianakis F, Koeppel T, Geldner G, Gahlen J (2005) [Carotid-surgery in ultrasound-guided anesthesia of the regio colli lateralis]. Anasthesio Intensivmed Notfallmed Schmerzther 40: 576-581.
18. Tissot S, Frering B, Gagnieu MC, Vallon JJ, Motin J (1997) Plasma concentrations of lidocaine and bupivacaine after cervical plexus block for carotid surgery. Anesth Analg 84:1377-1379.

19. Dhonneur G, Saidi NE, Merle JC, Asfazadourian H, Ndoko SK, et al. (2007) Demonstration of the spread of injectate with deep cervical plexus block: a case series. Reg Anesth Pain Med 32: 116-119.

20. Davies MJ, Silbert BS, Scott DA, Cook RJ, Mooney PH, et al. (1997) Superficial and deep cervical plexus block for carotid artery surgery: a prospective study of 1000 blocks. Reg Anesth 22: 442-446.

21. Pintaric TS, Hocevar M, Jereb S, Casati A, Jankovic VN (2007) A prospective, randomized comparison between combined (deep and superficial) and superficial cervical plexus block with levobupivacaine for minimally invasive parathyroidectomy. Anesth Analg 105: 1160-1163. 